\title{
The Effect of Pyrroloquinoline Quinone (PQQ) on Viability of Human Colorectal Adenocarcinoma HT-29 Cell Line
}

\author{
Marcos Flores-Encarnación $^{1 *}$, Itzel Cabrera-Aguilar ${ }^{1}$, Carlos Cabrera-Maldonado ${ }^{2}$, \\ Rosa María Nava-Nolazco ${ }^{1}$ \\ ${ }^{1}$ Laboratorio de Microbiología Molecular y Celular. Biomedicina. Facultad de Medicina. Benemérita \\ Universidad Autónoma de Puebla. Puebla, Puebla, México. \\ ${ }^{2}$ Depto. de Microbiología. Facultad de Ciencias Químicas. Benemérita Universidad Autónoma de Puebla. \\ Puebla, Puebla, México.
}

*Corresponding Author: Marcos Flores-Encarnación, Laboratorio de Microbiología Molecular y Celular. Biomedicina. Facultad de Medicina. Benemérita Universidad Autónoma de Puebla. Puebla, Puebla, México

\begin{abstract}
The pyrroloquinoline quinone $(P Q Q)$ is a polyphenolic compound. It has been proposed as a new vitamin. $P Q Q$ was first recognized as a bacterial cofactor. Today, it is known more about the chemicalbiological properties of $P Q Q$, especially of its beneficial impact on eukaryotic organisms. It has been reported that $P Q Q$ is a potent antioxidant and that it can function as a protector in cardiac lesions and others. The effect of PQQ on several cell lines also has been studied. The most relevant finding is that PQQ has induced apoptosis in cancer cells. This work shows some data about the effect of PQQ on the growth of human colorectal adenocarcinoma cell line HT-29.
\end{abstract}

Keywords: Pyrroloquinoline quinon, HT-29, line cell, PQQ, colorectal, adenocarcinoma.

\section{INTRODUCTION}

In recent studies, interest has been aroused in the study of a novel quinone, which could represent a good advance in natural medicine: pyrroloquinoline quinone (PQQ). PQQ is a polyphenolic compound, found in plants, animal cells, various foods and biological fluids. Several authors have proposed to PQQ as a new vitamin (Bauerly et al., 2011; Flores-Encarnación et al., 2014; Noji et al., 2007; Rucker et al., 2009). PQQ was first recognized as a bacterial cofactor in 1979, until date it has been purified and crystallized (Satyabrata et al., 2013; Stites et al., 2000). In the 90's, it was known more about its chemical-biological properties of PQQ. For example: it has been reported that PQQ functions as a potent cofactor in certain bacterial dehydrogenases (Flores-Encarnación et al., 2004). In animal cells, PQQ is involved in different signal transduction processes during cell growth, development, differentiation and cellular survival (Akagawa et al., 2016; Feng et al., 2014; Kimura et al., 2012). It has been reported that PQQ is a potent antioxidant (50-100 times more effective than ascorbic acid) (Rucker et al., 2009). It has been also reported that PQQ can function as a protector in cardiac lesions, prevents liver injury by eliminating free radicals, stimulates astrocytes and inhibits the generation of melanocytes in melanoma (Akagawa et al., 2016; Feng et al., 2014; Jia et al., 2015; Murase et al., 1993; Sato and Toriyama, 2009; Tao et al., 2007). In animal models, it has been shown that when PQQ is added to the diet ( $300 \mu \mathrm{g} / \mathrm{kg}$ body weight), reproduction and neonatal rates in rats and mice were increased (Harris et al., 2013).

In recent years, the use of PQQ has been proposed as an alternative treatment for prevention of Alzheimer's and Parkinson's diseases (Kobayashi et al., 2010a; Kobayashi et al., 2010b; Qin et al., 2016; Scanlon et al., 1997; Wang et al., 2014). Some neuroprotective mechanisms have been proposed, the most important is its high antioxidant potential, additional to PQQ crosses the cerebral barrier, protects mitochondria from oxidative damage, suppresses the formation of peroxynitrite and it prevents malformation of neuronal proteins (Kobayashi et al., 2010; Ohwada et al., 2006; Zhang et al., 2006). On the other hand, the effect of PQQ on several cell lines has been studied. The most relevant finding is that PQQ has induced apoptosis in cancer cells (Amador-Bravo et al., 2016; Min et 
al., 2014). Therefore, in this work are presented some data about the effect of PQQ on the growth of human colorectal adenocarcinoma cell line HT-29.

\section{MATERIAL AND MethodS}

\subsection{Chemical and Cell Line}

In this study PQQ commercially obtained by Sigma-Aldrich Co. was used. HT-29 (human colorectal adenocarcinoma) cell line was used and provided kindly by Dr. Juan Xicoténcatl from Hospital Infantil de México Federico Gómez.

\subsection{Cell Culture}

Culture of the colon cancer cell line was performed using a modification of the methodology described by Díaz et al., (2013) and Dupuy et al., (2013). For this, the cells in suspension were maintained in culture flasks and Petri dishes containing Eagle-Dulbecco's modified medium (DMEM) supplemented with $10 \%$ heat-inactivated fetal bovine serum, penicillin $\left(100 \mathrm{U} \mathrm{mL}^{-1}\right)$ and streptomycin $\left.(0.1 \mathrm{mg} \mathrm{mL})^{-1}\right)$. Cells were incubated at $37^{\circ} \mathrm{C}$ in a humidified atmosphere containing $5 \% \mathrm{CO}_{2}$.

\subsection{Counting and Cell Viability Assay}

The cell counting and viability assay was performed according to methodology described by Castillo et al., 2009. For this, $2 \mathrm{~mL}$ of the HT-29 cells in suspension were used. Subsequently, cells were centrifuged at $1,000 \mathrm{x} \mathrm{g}$ for 5 minutes. The pellet was resuspended in $20 \mu \mathrm{L}$ of fresh DMEM and 10 $\mu \mathrm{L}$ of cell suspension were placed in a Neubauer chamber for observation at $40 \mathrm{x}$. The cell viability assay was determined by mixing $10 \mu \mathrm{L}$ of the cell suspension (described above) with $10 \mu \mathrm{L}$ of $0.4 \%$ trypan blue incubating 5 minutes at room temperature. Then, $10 \mu \mathrm{L}$ of the mixture was placed in a Neubauer chamber for observation at 40x. Dead cells were observed in a deep blue color. All determinations were made in duplicate. As a positive control, the cells of Saccharomyces cerevisiae were used and they were grown at $30^{\circ} \mathrm{C}$ stirring at $150 \mathrm{rpm}$ for 24 hours. For negative control, nonviable cells of $S$. cerevisiae were used. This cells were obtained by heating at $50^{\circ} \mathrm{C}$ for 20 minutes.

\subsection{The Effect of PQQ on HT-29 Cell Line}

To determine the effect of PQQ on cell line, a 24-well culture plate containing $1 \mathrm{~mL}$ of DMEM medium added of $10 \%$ fetal bovine serum, penicillin $\left(100 \mathrm{U} \mathrm{mL}^{-1}\right)$, streptomycin $\left(0.1 \mathrm{mg} \mathrm{mL}^{-1}\right)$ and $1.3 \times 10^{4}$ cells/well was used. The different concentrations of PQQ were tested in the order of: $10 \mathrm{nM}$, $100 \mathrm{nM}$ and $1 \mu \mathrm{M}$ and $10 \mu \mathrm{M}$. The 24-well culture plate was incubated 48 hours at $37^{\circ} \mathrm{C}$ in a humidified atmosphere containing 5\% $\mathrm{CO}_{2}$. The effect of PQQ on HT-29 cell line was determinated using the viability assay according to the methodology described above and measuring the cell respiratory activity for each concentration of PQQ tested. The cell respiration was considered as an indirect measure of the effect of PQQ on metabolism. All determinations were made in duplicate.

\subsection{Respiratory Activity}

The respiratory activity was determinated by a polarographic method using a Clark electrode (FloresEncarnación et al., 1999). Briefly, $8.6 \times 10^{4}$ cells $\mathrm{mL}^{-1}$ were placed in well of a 24 -well culture plate containing $500 \mu \mathrm{L}$ of fresh DMEM medium. The Clark electrode was placed in the well. The assay was started by adding $100 \mu \mathrm{L}$ of $0.7 \mathrm{M}$ glucose and and oxygen consumption was recorded. The assay was performed at $37^{\circ} \mathrm{C}$. As control, a test was performed by placing $4 \times 10^{7}$ cells mll of $S$. cerevisiae (24-hour culture), $500 \mu \mathrm{L}$ of fresh DMEM medium and $100 \mu \mathrm{L}$ of $0.7 \mathrm{M}$ glucose. The assay was performed at $30^{\circ} \mathrm{C}$. The negative control consisted of an assay in which there was no addition of glucose.

\section{RESUltS}

To test the effect of PQQ on viability, human colorectal adenocarcinoma HT-29 cells were incubated 48 hours with PQQ in a 24-well culture plate containing DMEM medium, fetal bovine serum and antibiotics. The concentrations of PQQ tested were: $10 \mathrm{nM}, 100 \mathrm{nM}, 1 \mu \mathrm{M}$ and $10 \mu \mathrm{M}$, as described in Materials and Methods. The cell viability was determined using $0.4 \%$ trypan blue and incubating at room temperature. The results indicated that HT-29 cells showed a characteristic morphology of the cell line and PQQ apparently had no significant effect on morphology and cell viability (observating the cells at 40x), when the HT-29 cells were incubated at low concentrations of PQQ (10 and $100 \mathrm{nM})$ 
(Fig. 1). However, when the HT-29 cells were incubated at higher concentrations of PQQ (1 and 10 $\mu \mathrm{M})$, the morphology changed and cell viability decreased markedly. The Fig. 1D and Fig. 1E shown a marked increase in the number of dead cells (blue colored). According to the results obtained, it seems that PQQ produced the death of the HT-29 cells when concentrations in the order micromolar were used.

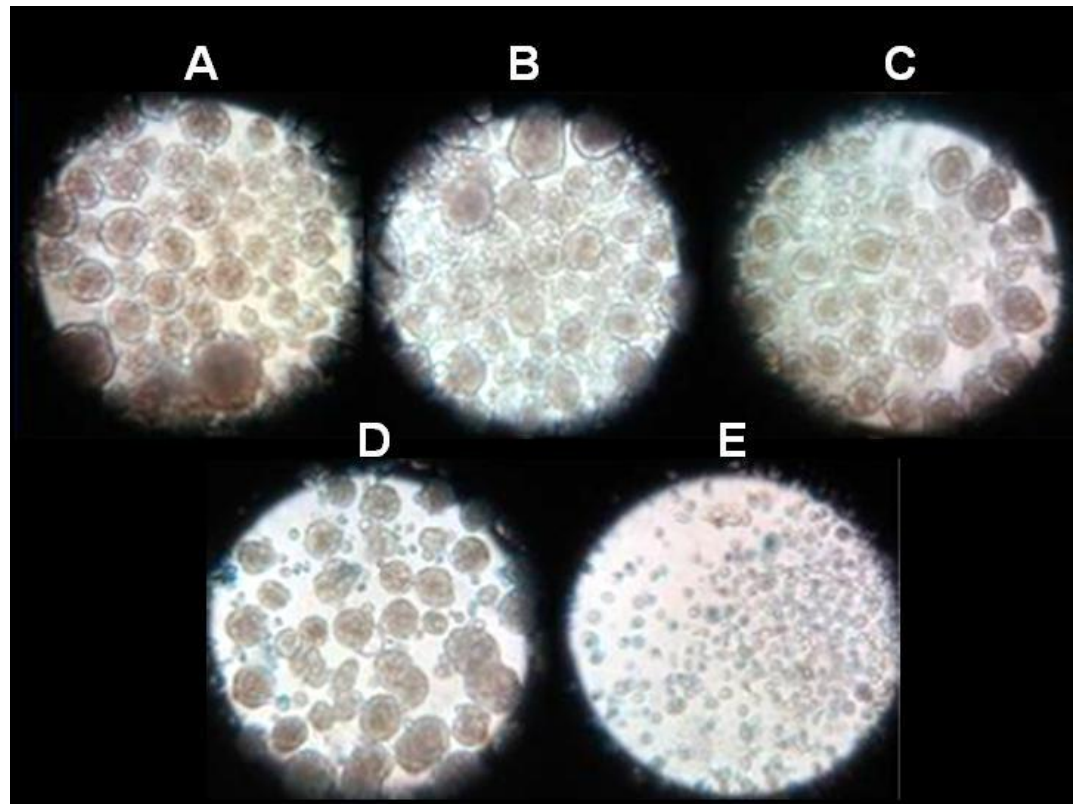

Fig1. The effect of PQQ on morphology of HT-29 cells at 40x. A. Without PQQ; B. 10 nM PQQ; C. 100 nM PQQ; D. $1 \mu M$ PQQ; E. $10 \mu M$ PQQ

After that, it proceeded to determine the cellular viability using $0.4 \%$ trypan blue in a Neubauer chamber for HT-29 cells that were incubated in the presence of different concentrations of PQQ. The results are shown in Table 1. As seen in Table 1, almost $80 \%$ of the HT-29 cells tested were viable in the absence of PQQ. In this study, it was observed that when the cells were incubated in the presence of PQQ, the cell viability counts decreased which was in agreement with what was observed in light field microscopies. Thus, the results showed that at the highest concentration tested of PQQ $(10 \mu \mathrm{M})$, the viability of HT-29 cells decreased to $35 \%$. Considering the control condition of this assay that showed a cell viability of approximately $80 \%$, the actual arrest of cell viability using $10 \mu \mathrm{M}$ PQQ was approximately 56\%. Therefore, an increase in the concentration of PQQ produced a decrease in the viability of HT-29 cells.

The effect of PQQ was also determinated measuring the respiratory activity of HT-29 cells. For this a Clark electrode was used and HT-29 cells were placed in a 24-well culture plate containing fresh DMEM medium. The oxygen consumption was recorded after adding of glucose to the reaction mixture. The results are shown in Table 2. As seen in Table 2, the methodology used allowed to measure the respiration rates of HT-29 cells. The control condition recorded a value of $0.421 \mathrm{nmol} \mathrm{O}$ consumed $\mathrm{min}^{-1}$, while the HT-29 cells incubated in PQQ $(10 \mathrm{nM}, 100 \mathrm{nM}$ and $1 \mu \mathrm{M})$ showed similar respiratory rates to control condition; but not for the concentration $10 \mu \mathrm{M}$ PQQ where there was a decrease in respiratory activity. These data are related to the cell viability recorded for the concentrations of PQQ used. The respiratory activities confirmed: the viability of HT-29 cells after they were exposed to PQQ; at higher concentrations (such as $10 \mu \mathrm{M}$ ) the destruction of the cells was favored.

Table1. The effect of $P Q Q$ on cell viability

\begin{tabular}{|l|l|l|}
\hline PQQ concentration & Cell viability (\%) & Relative cell viability (\%) $^{\text {a }}$ \\
\hline $0 \mathrm{nM}$ & 79.23 & 100.00 \\
\hline $10 \mathrm{nM}$ & 70.00 & 88.35 \\
\hline $100 \mathrm{nM}$ & 60.86 & 76.81 \\
\hline $1 \mu \mathrm{M}$ & 38.67 & 48.80 \\
\hline $10 \mu \mathrm{M}$ & 34.96 & 44.12 \\
\hline
\end{tabular}

${ }^{a}$ Referred to cellular viability recorded in the absence of $P Q Q$

International Journal of Research Studies in Biosciences (IJRSB) 
The Effect of Pyrroloquinoline Quinone (PQQ) on Viability of Human Colorectal Adenocarcinoma HT29 Cell Line

Table2. The effect of $P Q Q$ on the respiratory activity of $H T-29$ cells

\begin{tabular}{|l|l|l|}
\hline PQQ concentration & Respiratory activity $\left(\mathbf{n m o l ~} \mathbf{O}_{\mathbf{2}} \mathbf{~ m i n}^{-\mathbf{1}}\right)$ & Cell viability (\%) \\
\hline $0 \mathrm{nM}$ & 0.421 & 79.23 \\
\hline $10 \mathrm{nM}$ & 0.512 & 70.00 \\
\hline $100 \mathrm{nM}$ & 0.521 & 60.86 \\
\hline $1 \mu \mathrm{M}$ & 0.532 & 38.67 \\
\hline $10 \mu \mathrm{M}$ & 0.386 & 34.96 \\
\hline
\end{tabular}

\section{DISCUSSION}

Various examples of bacterial quinoproteins have been described, which are known to contain $o-$ quinones as cofactors (Amador-Bravo et al., 2016; Flores-Encarnación et al., 2004; Rucker et al., 2009; Satyabrata et al., 2013; Stites et al., 2000). It has been studied more to PQQ-dependent enzymes, including PQQ-dehydrogenases, which incompletely oxidized sugars, alcohols, aldehydes, organic acids and they are present in different Gram-negative bacteria (Stites et al., 2000). For example: PQQ-alcohol dehydrogenase (A-DH) and PQQ-aldehyde dehydrogenase (AL-DH) from Acetobacter aceti and Gluconobacter oxydans are enzymes responsible for acetic acid production (Amador-Bravo et al., 2016; Flores-Encarnación et al., 2014; Tao et al., 2007).

Although PQQ was discovered in bacteria, in recent years different functions have been described for this cofactor in higher organisms, for example: free radical scavenger, cataract inhibitor, animal and plant's development and growth promoter, among others (Flores-Encarnación et al., 2014; Rucker et al., 2009). PQQ has been classified as a vitamin and as an essential nutrient. It has also been reported that PQQ increases cognitive ability and promotes energy metabolism (Ohwada et al., 2008; Wang et al., 2014). Some reports indicates that PQQ plays an important role in cell proliferation and being a powerful antioxidant, it has been observed that prevents lipoperoxidation (Azizi et al., 2014; Shui et al., 2015). There is no evidence that PQQ can be synthesized in cells of higher organisms (mammals). However, PQQ has been detected in low quantities (in the order of nanograms) in human serum, breast milk, in different plants and foods such as kiwi, egg, milk and in fermented products such as sake and wine (Noji et al., 2007). It has been suggested that PQQ, present in the human organism, could have its origin from the bacteria present in the digestive tract, although it is not known precisely the functions that PQQ could perform in humans. There are several studies that could provide information about this. Like some studies that have consisted on the exogenous addition of PQQ using cell cultures and animal models (Stites et al., 2000). For example, in NIH3T3 mouse fibroblasts, it was observed that PQQ increased cell proliferation, whereas in the BALBc/3T3 cell line, PQQ potentiated the synthesis of the growth factor (Murase et al., 1993). As a free radical scavenger, PQQ has been reported to increase nerve growth factor (NGF) concentrations in astrocytes and it inhibits melanin production in melanoma cells (Wang et al., 2014). In animal models, PQQ has been reported to have a cardioprotective effect, as well as to prevent hepatic alcohol damage (Jia et al., 2015).

Thus in the present study, it was determined the effect of PQQ on the viability of HT-29 cells from human colorectal adenocarcinoma. The results showed that when the HT-29 cells were incubated at low concentrations of PQQ (10 and $100 \mathrm{nM})$ there was no effect on morphology and cell and viability and that when the HT-29 cells were incubated at higher concentrations of PQQ (1and $10 \mu \mathrm{M})$, the morphology changed and cell viability decreased (Fig. 1). According to the results obtained, the HT29 cells died when concentrations in the order micromolar were used. It has been reported that PQQ suppressed cell proliferation on tumor cell lines, like human lung adenocarcinoma, mouse neuroblastoma and human hepatocellular carcinoma (Min et al., 2014). in the present study, the results showed that at the highest concentration tested of PQQ $(10 \mu \mathrm{M})$, the viability of HT-29 cells decreased to $35 \%-56 \%$ (Table 1). An increase in the concentration of PQQ produced a decrease in the viability of HT-29 cells. Therefore, the use of a concentration much higher than $10 \mu \mathrm{M}$ of PQQ should produce a more lethal effect on HT-29 cells, however this was not done in this study. In this context, the present study determined the effect of PQQ on a colon cancer cell line to know about its possible antiproliferative effects. Although 100\% inhibition of growth of HT-29 cells was not achieved, valuable information was obtained suggesting that PQQ caused the death of colon cancer cells at the concentrations tested. The mechanism of action is unknown, however some authors have proposed that PQQ binds to certain receptors embedded in the cell membrane and that the receptors 
activate proteins that can detonate either cell proliferation and mitochondrial biogenesis or apoptosis (Rucker et al., 2009). It has been proposed that PQQ in other cell lines induces apoptosis by activating some cell death signals, forming a complex between DJ-1 (protein involved in oxidative stress) and Daxx (apoptosis-associated protein), a complex that modulates apoptosis through the activation of the JNK pathway (Janus N-terminal kinase) or the caspase pathway (Rucker et al., 2009; Stites et al., 2006). It has been reported that PQQ has beneficial effects on healthy cells at nanomolar concentrations. For example, excess of glutamate is known to induce apoptosis in progenitor and neural stem cells (NS/PCs). However, it was observed that when growing these cells in the presence of exogenous PQQ at concentrations between 3 and $30 \mu \mathrm{M}$, there was an increase in cell proliferation and a significant reduction of glutamate induced cell damage (Shui et al., 2015). PQQ has been tested in conjunction with vitamin $\mathrm{E}$ and it was found that the recovery of peripheral nerve lesions is favored, stimulating the regeneration of axons in a shorter time (Azizi et al., 2014).

In this study, the effect of PQQ was also determinated measuring the respiratory activity of HT-29 cells. The results shown that a concentration $10 \mu \mathrm{M}$ PQQ produced a decrease in respiratory activity and that at low concentrations of PQQ the respiration of the remaining cells was potentiated (Table 2). Apparently the observed effects depended on the concentration of PQQ, which led to the proposition that this cofactor could be acting at different levels (perhaps in different signaling pathways). This is related to data reported in the literature, since tumor cells can reprogram glucose metabolism and decrease mitochondrial metabolism, generating ATP from aerobic or anaerobic glycolysis (Valle and Soto, 2014; Wu and Zhao, 2013). Mitochondrial oxidative metabolism could be affected favoring respiration with glucose (glycolytic pathway). As has been reported, active glycolysis leads to the production of lactic acid, which when accumulated generates a highly damaging environment for cells (Valle and Soto, 2014; Wu and Zhao, 2013;). Therefore, in this work at concentrations higher of PQQ, excessive accumulation of lactic acid could explain the considerable increase in the mortality of the cells tested and with that, the decrease in cellular respiration. Lactic acid was not quantified, however a change in $\mathrm{pH}$ in the culture medium could be observed: it was acidified in growing cells (data not shown). Kimura et al., (2012) reported that PQQ produces two different effects on cell lines depending on the concentration tested in A431 line from human epithelial cell carcinoma. PQQ (in nanomolar concentration) produced cell proliferation, functioning as a vitamin and having an increase of $180 \%$, in contrast PQQ in micromolar concentrations induced apoptosis (Kimura et al., 2012). Shankar et al., (2010) reported that PQQ at concentrations of 50-100 $\mu \mathrm{M}$ produced apoptosis in U937 cell line from human promonocytic leukemia. Melanoma is caused when melanocytes produce a large amount of tyrosinase enzyme involved in melanin synthesis. In high concentrations, the melanin causes hyperpigmentation of the skin and even cancer (Feng et al., 2014). It has been reported that in B16F1cell line from murine melanoma, PQQ inhibited the expression of tyrosinase's mRNA, preventing melanin production and that $25 \mu \mathrm{M}$ PQQ reduced melanin production by up to $62 \%$ (Sato et al., 2009). The mechanisms of action are unknown, however PQQ could be an alternative treatment against melanogenesis and hyperpigmentation disorders (Sato et al., 2009). In other studies it has been reported that in different cells lines such as human lung adenocarcinoma A-549, mouse neuroblastoma neuro-2A and human hepatocellular carcinoma HCC-LM3, PQQ suppressed the cell proliferation through the apoptotic pathway: cellular activity of caspase-3, arrest of the cell cycle in the Go/G1 phase, with accumulation of intracellular reactive oxygen species (ROS) and a low ATP level (Min et al., 2014). The effects caused by the addition of PQQ were observed using the concentrations of $30 \mu \mathrm{M}$ to $75 \mu \mathrm{M}$ (Min et al., 2014). Finally, the effects of PQQ on cell lines appear to be varied, concentration dependent and activating different signaling pathways.

\section{CONCLUSION}

PQQ is a molecule of bacterial origin with great biological potential in eukaryotic organisms. In recent years, it has been reported that PQQ produce beneficial effects in animal models in which the molecule has been tested. One of those benefits is to kill to cancer-related cell lines. In this study, some evidence of the deleterious effect of PQQ on HT-29 cells from human colorectal adenocarcinoma were shown. This effect was observed when PQQ were used in concentrations in the micromolar order of PQQ. It is important to do more studies on the effects of PQQ to better understand its function and its possible use as an alternative cancer therapy. 


\section{ACKNOWLEDGEMENTS}

We are grateful for the kind collaboration and critical contributions to the present work of Dr. Mariano Sánchez Cuevas from Dean of Biological Sciences-UPAEP and Dr. Juan Ángel Alonso Avelino from Facultad de Medicina-UPAEP. Also Thank to Dr. Juan Xicohténcatl for the valuable technical collaboration for the development of this work. Thank to VIEP-BUAP and PRODEP for the facilities provied for the development of this work.

\section{REFERENCES}

[1] Akagawa, M., Nakano, M. and Ikemoto, K. (2016). Recent progress in studies on the health benefits of pyrroloquinolinequinone. Biosc. Biotechnol. Biochem. 80:13-22.

[2] Amador-Bravo, D., Flores-Encarnación, M., Aguilar-Gutiérrez, G.R. and Sánchez-Cuevas, M. (2016). Pyrroloquinoline quinone: a brief overview of its biological potencial. Basic Res. J. Med. Clin. Sci. 5:0105 .

[3] Azizi, A., Azizi, S., Heshmatian, B. and Amini K. (2014). Improvement of functional recovery of transected peripheral nerve by means of chitosan grafts filles with vitamin $\mathrm{E}$, pyrroloquinoline quinone and their combination. Intern. J. Surg. 12:76-82.

[4] Bauerly, K., Harris, C., Chowanidisai, W., Graham, J., Havel, P., Tchaparian, E., Satre, M., Karliner, J. and Rucker, R. (2011). Altering pyrroloquinoline quinone nutritional status modulates mitochondrial, lipid, and energy metabolism in rats. PLoS ONE. e21779.

[5] Castillo, Y., Sierra, A., Martínez, A. and Plenge, F. (2009). Efecto del diazinón sobre el cultivo de linfocitos de sangre periférica de humano. Tecnociencia Chihuahua. 3:97-106.

[6] Díaz, A., Morier, L., Frión, Y., Rodríguez, H., Caballero, Y., Mendoza, D., Riquenes, Y. and Fraga, J. (2013). In vitro anticancer effect of venom from Cuban scorpion Rhopalurus junceus against a panel of human cancer cell lines. J. Venom Res. 4:5-12.

[7] Dupuy, O., Bonilla, J., Murillo, R., Taylor, P., Abad, M., González, L. and Juliao, J. (2013). Efecto in vitro de los terpenos lupeol y casearina G sobre células sanguíneas y tumorales. Rev. Méd. Chile. 141:11501157.

[8] Feng, X., Haixia, Y., Jinyao, L. and Lu, C. (2014). Pyrroloquinoline quinone inhibits oxygen/glucose deprivation-induced apoptosis by activating the PI3K/AKT pathway in cardiomyocytes. Mol. Cel. Biochem. 386:107-115.

[9] Flores-Encarnación, M., Contreras-Zentella M., Soto-Urzua L., Aguilar G.R. Baca E. and Escamilla J.E. (1999). The respiratory system and diazotrophic activity of Acetobacter diazotrophicus PAL5. J. Bacteriol. 181:6987-6995.

[10] Flores-Encarnación, M., González-Gutiérrez, J., Amador-Bravo, D., Bravo-Juárez, L., CabreraMaldonado, C. (2014). A bacterial novel quinone participating in multiple functions in higher organisms. Global Adv. Res. J. Med. and Medical Sci. 3:132-138.

[11] Flores-Encarnación, M., Sánchez-Cuevas, M. and Ortiz-Gutiérrez, F. (2004). Las PQQ-deshidrogenasas. Un novedoso ejemplo de quinoproteínas bacterianas. Rev. Latinoamer. Microbiol. 46:47-59.

[12] Harris, C., Chowanadisai, W., Mishchuk, D., Satre, M., Slupsky, C. and Rucker, R. (2013). Dietary pyrroloquinoline quinone (PQQ) alters indicators of inflammation and mitochondrial-related metabolism in human subjects. J. Nut. Biochem. 24:2076-2084.

[13] Jia, D., Duan, F., Peng, P., Sun, L., Ruan, Y. and Gu, J. (2015). Pyrroloquinoline quinone suppresses liver fibrogenesis in mice. PLoS ONE. 10:e0121939.

[14] Kimura, K., Takada, M., Ishii, T., Tsuji-Naito, K. and Akagawa, M. (2012). Pyrroloquinoline quinone stimulates epithelial cell proliferation by activating epidermal growth factor receptor through redox cycling. Free Rad. Biol. Med. 53:1239-1251.

[15] Kobayashi, M., Kim, J., Fukuda, M., Ogasawara, D., Kobayashi, N., Han, S., Nakamura, C., Inada, M., Miyaura, C., Ikebukuro, K. and Sode, K. (2010a). Pyrroloquinoline quinone inhibits the fibrillation of amyloid proteins. Prion. 4:26-31.

[16] Kobayashi, M., Kim, J., Harada, R., Kobayashi, N. and Sode, K. (2010b). The inhibitory effect of pyrroloquinoline quinone on the amyloid formation and cytotoxicity of truncated alpha-synuclein. Mol. Neurodeg. 5:20-31.

[17] Min, Z., Wang, L., Jin, J., Wang, X., Zhu, B., Chen, H. and Cheng, Y. (2014). Pyrroloquinoline quinone induces cancer cell apoptosis via mitochondrial-dependent pathway and down-regulating cellular Bcl-2 protein expression. J. Cancer. 5:609-624.

[18] Murase, K., Hattori, A., Kohno, M. and Hayashi, K. (1993). Stimulation of nerve growth factor synthesis/secretion in mouse astroglial cells by coenzymes. Biochem. Mol. Biol. Inter. 30:615-621. 
[19] Noji, N., Nakamura, T., Kitahata, N., Taguchi, K., Kudo, T., Yoshida, S., Tsujimoto, M., Sugiyama, T. and Asami, T. (2007). Simple and sensitive method for pyrroloquinoline quinone (PQQ) analysis in various foods using liquid chromatography/electrospray-ionization tandem mass spectrometry. J. Agric. Food Chem. 55:7258-7263.

[20] Ohwada, K., Takeda, H., Yamazaki, M., Isogai, H., Nakano, M., Shimomura, M., Fukui, K. and Urano, S. (2008). Pyrroloquinoline quinone (PQQ) prevents cognitive deficit caused by oxidative stress in rats. J. Clin. Biochem. Nut. 42:29-34.

[21] Qin, J., Meilong, W., Shu, Y., Xiaorong, G., Jingjing, Z., Xingyue, D., Jinyan, J., Yuxi, Z., Lin, Z, Qi, Z. and Fei, D. (2016). Pyrroloquinoline quinone-conferred neuroprotection in rotenone models of Parkinson's disease. Toxicol. Lett. 238:70-82.

[22] Rucker, R., Chowanadisai, W. and Nakano, M. (2009). Potential physiological importance of pyrroloquinoline quinone. Altern. Med. Review. 14:268-277.

[23] Sato, K. and Toriyama, M. (2009). Effect of pyrroloquinoline quinone (PQQ) on melanogenic protein expression in murine B16 melanoma. J. Demartol. Sci. 53:140-145.

[24] Satyabrata, G., Runu, C. and Utpal, R. (2013). Pyrroloquinoline quinone a redox cofactor and its involvement in biological system. Inter. J. Sci. Nat. 4:371-380.

[25] Scanlon, J., Aizenman, E. and Reynolds, I. (1997). Effects of pyrroloquinoline quinone on glutamateinduced production of reactive oxygen species in neurons. Eur. J. Pharmacol. 326:67-74.

[26] Shankar, B., Pandey, R., Amin, P., Misra, H. and Sainis, K. (2010). Role of glutathione in augmenting the anticancer activity of pyrroloquinoline quinone (PQQ). Redox Report. 15:146-154.

[27] Shui, G., Jianqiang, X., Yifu, G., Dan, G., Tianqing, L., Xuehu, M. and Zhanfeng, C. (2015). Pyrroloquinoline quinone against glutamate-induced neurotoxicity in cultured neural stem and progenitor cells. Inter. J. Develop. Neurosci. 42:37-45.

[28] Stites, T., Mitchell, A. and Rucker, R. (2000). Physiological importance of quinoenzymes and the $o$ quinone family of cofactors. The J. Nut. 130:719-727.

[29] Tao, R., Karliner, J., Simonis, U., Zheng, J., Zhang, J., Honbo, N. and Alano, C. (2007). Pyrroloquinoline quinone preserves mitochondrial function and prevents oxidative injury in adult rat cardiac myocytes. Biochem. Biophys. Res. Comm. 363:257-262.

[30] Valle, A. and Soto, I. (2014). Metabolismo energético y cáncer. Vertientes. 17:108-113.

[31] Wang, Z., Chen, G., Yu, G. and Liu, C. (2014). Pyrroloquinoline quinone protects mouse brain endothelial cells from high glucose-induced damage in vitro. Acta Pharmacol. Sinica. 35:1402-1410.

[32] Wu, W. and Zhao, S. (2013). Metabolic changes in cancer: beyond the Warburg effect. Acta Biochim. Biophys. Sinica. 45:18-26.

[33] Zhang, Y., Feustel, P. and Kimelberg, H. (2006). Neuroprotection by pyrroloquinoline quinone (PQQ) in reversible middle cerebral artery occlusion in the adult rat. Brain Res. 1094:200-206.

Citation: M. Flores-Encarnación et al., "The Effect of Pyrroloquinoline Quinone (PQQ) on Viability of Human Colorectal Adenocarcinoma HT-29 Cell Line", International Journal of Research Studies in Biosciences (IJRSB), vol. 5, no. 10, pp. 18-24, 2017. http://dx.doi.org/10.20431/2349-0365.0510004

Copyright: () 2017 Authors. This is an open-access article distributed under the terms of the Creative Commons Attribution License, which permits unrestricted use, distribution, and reproduction in any medium, provided the original author and source are credited. 